\title{
KARYOTYPE OF THE BLUE CHRYSOMELID OF ACEROLA, LEUCOCERA LAEVICOLLIS WEISE (COLEOPTERA, CHRYSOMELIDAE)
}

Specimens of this insect, the blue chrysomelid of acerola, were obtained through the courtesy of Dr. Luis F. Martorell and Mr. J. C. García Tuduri, ${ }^{1}$ for conducting cytological studies. They have been studying this species, which causes considerable damage to the native acerola tree, Malpighia punicifolia. This bright-blue coleopteran belongs to the family Chrysomelidae. It has been recorded in Puerto Rico since $1922^{2}$. The specimens

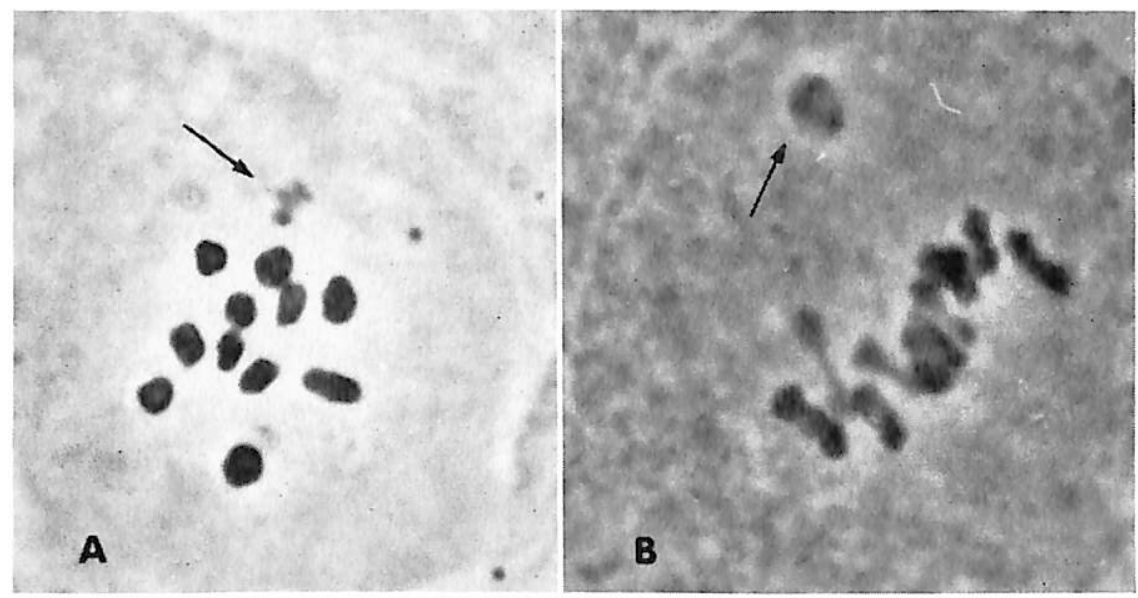

FIG. 1. First meiotic division of male Leucocera laevicollis. $11^{\mathrm{II}}+X_{y_{p}}$; sex bivalent marked with arrow. Phase contrast. Magnification $2130 \times$ : A, Prometaphase; $X_{y_{p}}$ negatively heteropycnotic and tripartite; $\mathrm{B}$, metaphase; observe the position of $X_{y_{p}}$.

studied were all collected at an acerola farm located in the Barrio Monterrey, between Vega Alta and Dorado.

The specimens were kept alive in the laboratory in a petri dish, and were fed fresh acerola leaves. They were dissected, and the testes located and fixed for nearly 2 minutes in Kahle-Smith solution. Squashes were made in a 45-percent acetic acid medium. No staining was effected and the slides were studied under phase microscopy in a Zeiss photomicroscope.

The karyotype of the species was determined to be $11^{1 \mathrm{II}}+X_{y_{p}}$ (fig. 1).

${ }^{1}$ Entomologist, Head of Department, and Assistant Entomologist, respectively, Department of Entomology, Agricultural Experiment Station, Mayagüez Campüs, Río Piedras, P.R.

${ }^{2}$ Wolcott, G. N., The Insects of Puerto Rico, J. Agr. Univ. P.R. 32(2): 225-416, 1948. 
The structure of the conjugated sex chromosomes was not easy to determine at the beginning, since, in several instances, the bivalent appeared tripartite and tetrapartite, a condition which can better be explained as being caused by the arms of metacentric sex chromosomes when the centromeric region exhibits a prominent gap. This karyotype has already been determined by $\mathrm{Smith}^{3}$ in the genus Calligrapha, family Chrysomelidae, subfamily Chrysomelinae.

In adults, the most prominent meiotic phases were late prophase through early metaphase. Hardly any anaphases or very early prophase were encountered. For that reason it was not possible to determine actually the location of the centromere in the remaining autosomes, though most probably they are metacentric.

The behavior of the sex chromosomes in late prophase does not follow the pattern established by the autosomes. This stage is marked by the clumping of the autosomes in association, following the disintegration of the nuclear membrane. The sex chromosomes do not participate in this activity. This has been observed previously by Virkki ${ }^{4}$ in Geotrupes stercorarius, a scarabaeid beetle. This exceptional behavior of the sex bivalent is recognizable until the end of metaphase 1 (fig. 1,B).

Carmen Albizu de Santiago

Department of Plant Breeding

\footnotetext{
${ }^{3}$ Smith, S. G., Chromosome Numbers of Coleoptera, Heredity 7: 31-48, 1953.

1 Virkki, N., Zur Zytologie einiger Scarabaeiden (Coleoptera), Ann. Zool. Soc. "Vanamo" 14(3): 1-107, 1951.
} 